DOI: http://dx.doi.org/10.22483/2177-5796.2018v20n2p357-369

\title{
O que Paulo Freire tem a nos dizer
}

\author{
Pedro Laudinor Goergen
}

Resumo: O presente texto se propõe falar de Paulo Freire desde a perspectiva de alguém que não só conhece sua obra, mas que também conviveu academicamente com o autor. Não se trata de seguir trilha meramente subjetivista, mas de construir uma abordagem que respeite a forma de pensar, de escrever e de ser de Paulo Freire pensador, professor e autor. Sem esta visão peculiar do trabalho de Freire, corre-se o risco de perder um aspecto importante e, talvez, essencial de sua postura pedagógica cujo sentido maior era superar as posturas classistas inerentes ao tecido fiado segundo moldes capitalistas. Para Freire, o reconhecimento de todos os seres humanos como iguais e o incremento de estratégias concretas, práticas e factíveis, para alcançar este ideal era o sentido maior e último da educação. Duas estratégias parecem a Freire essenciais: primeiro a conscientização do princípio antropológico da igualdade e, segundo, a busca de estratégias de superação das diferenças mediante o acesso à cultura pela educação. O objetivo da presente reflexão é prestar reconhecimento à sua obra e dar azo a alguns impulsos reflexivos a partir de seus pensamentos.

Palavras-chave: Paulo Freire. Educação libertária. Pedagogia do oprimido.

\section{What Paulo Freire has to tell us}

\begin{abstract}
The present text intends to talk about Paulo Freire from the perspective of someone who not only knows his work but also lived with the author academically. Is is not a question of following a merely subjectivist path, but of constructing an approach that respects the thinking, writing and being of Paulo Freire, thinker teacher and author. Without this peculiar view of Freire's work, there is a risk of losing an important and perhaps an essential aspect of his pedagogical posture, whose main purpose was the overcome the classist postures inherent in the fabric woven according to the capitalist molds. For Freire, the recongnition of all human beings as equals and the increment of concrete, practical and feasible strategies to reach this ideal was the highest and ultimate meaning of education. Two strategies seem essential to him: first, awareness of the anthropological principle of equality and, secondly, the search of strategies to overcome differences through access to culture through education. The purpose of the present reflection is to give recognition of this work and give rise to some reflexive impulses from his thoughts.
\end{abstract}

Keywords: Paulo Freire. Libertarian education. Pedagogy of the oppressed. 


\section{Introdução}

Escrever sobre Paulo Freire é para mim tarefa singular porque convivi alguns anos com ele na Faculdade de Educação da Unicamp. Em muitos momentos, especialmente naqueles mais informais, beirava o inacreditável ver aquele homem tão conhecido e reconhecido mundo afora como um dos grandes revolucionários da educação, estar ali, simples, conversador, brincalhão, desprendido, comendo do prato de plástico e tomando cerveja com estudantes e professores. Nesses momentos, lembrava dos tempos do meu doutorado na Universidade de Munique quando nós, estudantes brasileiros, nos reuníamos para ouvir 'afaste de mim este cálice' de Chico Buarque e quase sempre lembrávamos com orgulho de Paulo Freire que, nesta época, costumo dizer, era tão conhecido na Europa quanto Pelé. Na Europa da década de 70, Paulo Freire era uma das personalidades mais conhecidas, era mesmo popular. Seu nome circulava não só nas universidades, mas nas escolas e entre os estudantes. Os jovens sabiam quem era Pelé e sabiam quem era Paulo Freire. Pessoalmente, escrevo este texto como admirador de um grande reformador do pensamento pedagógico brasileiro e internacional e como alguém que reconhece a importância de Paulo Freire para pensar a educação hoje.

Em 1980, quando a ditadura já definhava, Paulo Freire veio para a Unicamp. Juntava-se a outros intelectuais importantes que lideravam os grandes debates a educação nacional: Luiz Antonio Cunha, Rubem Alves, Laymert Garcia dos Santos, Maurício Tragtenberg, Roberto Romano, Antonio Muniz de Resende, Dermeval Saviani, Vanilda Paiva, Moacir Gadotti, Casemiro dos Reis Filho, Ivany Pino, esta última, então, Coordenadora do Departamento de Sociologia da Educação onde Paulo Freire foi acolhido. Ao mesmo tempo, lecionava na Pontifícia Universidade Católica de São Paulo e viajava pelo país proferindo palestras.

Foi também nesse período que Paulo Freire foi convidado pelo Prof. Aldo Vannucchi, então Diretor da Faculdade de Filosofia Ciências e Letras de Sorocaba, para pronunciar três palestras, realizadas nos dias 24/10/80, 31/10/80, 7/11/80. No ano seguinte retornaria para mais uma conferência no dia 7/11/81, desta vez a convite do Partido dos Trabalhadores e da Associação dos Professores. Não importa aqui dedicar mais tempo a referências históricas que são públicas e facilmente acessíveis. Causa surpresa, embora se explique, que no contexto das atuais precedências político-econômicas Paulo Freire seja hoje pouco conhecido entre a maioria dos brasileiros, até no meio acadêmico, com exceção, talvez, da área de educação, mesmo sendo 
ele o Patrono da Educação Brasileira. Muitos, da direita à esquerda, olham com um certo desdém para o educador brasileiro, ao contrário do que acontece, por exemplo, na Argentina.

Independente disso, há hoje inúmeras publicações, artigos, livros, dissertações e teses dedicadas ao estudo do pensamento de Freire, destacando sua relevância e originalidade para a educação brasileira e mundial. O presente texto não objetiva mais que chamar a atenção para a atualidade de Freire num cenário político-econômico de profundas desorientações e incertezas, mas, sobretudo, de normatividade pragmático/econômica que define hoje a subjetividade e as relações sociais.

\section{I}

Quando se fala de Paulo Freire, imediatamente nos vem à mente a história de Angicos, uma pequena cidade do Rio Grande do Norte onde Freire coordenou um projeto de alfabetização de adultos que, depois, entraria na história da educação nacional e internacional. A intuição e percepção inicial de Freire foi a de que o método empregado na educação de adultos era o mesmo usado na educação de crianças. Isso lhe pareceu não só pedagogicamente inadequado, quanto mais, humilhante para os adultos. Em 1958, apresentou as bases teóricas de seu novo método de alfabetização de Adultos no Segundo Congresso Nacional de Educação de Adultos, realizado no Rio de Janeiro.

Seria inadequado imaginar que as ideias de Freire a respeito da especificidade e importância da educação de adultos tivessem irrompido como do nada. Ao contrário, havia um contexto de mobilização política no nordeste brasileiro contra a miséria e a ignorância do povo. Em 1960, logo no início de seu mandato, Miguel Arraes, o lendário prefeito de Recife, criou o 'Movimento de cultura popular' (MPC) que teve Paulo Freire como um de seus participantes e articuladores.

Os ideais do MPC rapidamente se difundiram no Nordeste, por meio dos círculos de cultura, associando a cultura popular à luta política de transformação social. A primeira experiência com o chamado 'projeto Paulo Freire' foi realizado no Centro Dona Olegarinha, em 1962. Um ano após, o MEC (quem diria) promoveu o I Encontro Nacional de Alfabetização e Cultura popular. Iniciativas semelhantes foram lançadas pelo Secretário de Educação de Natal, 
Moacyr Góes com a campanha 'De pé no chão também se aprende a ler'. Estes projetos consideravam educação e cultura como instrumentos de libertação.

Nesse mesmo período, a Igreja Católica lançava o Movimento de Educação de Base (MEB), utilizando a rede de emissoras católicas e a União Nacional dos estudantes (UNE) criava o Centro Popular de Cultura, abrindo caminho para a politização das questões sociais. Pois, é nesse contexto que o Secretário de Educação do Rio Grande do Norte, Calazans Fernandes, e seus colaboradores idealizaram o Programa de Alfabetização de Angicos e convidaram Paulo Freire para coordenar o projeto. O ponto de partida foi o levantamento empírico do número de analfabetos e do seu universo vocabular (palavras e temas geradores). O objetivo geral era alfabetizar 100.000 adultos e adolescentes até 1965.

O projeto foi lançado no dia 18 de janeiro de 1963 com a presença de Aluísio Alves, Governador do Estado do Rio Grande do Norte, acolhendo moradores de Angicos para iniciarem sua alfabetização. A aula inaugural foi realizada no dia 24 de janeiro, sobre o tema " $O$ conceito antropológico de cultura tendo como palavra geradora 'belota". A primeira turma de 300 alunos concluiu o curso em 2 de abril de 1963, com a presença do Presidente da República João Goulart e vários governadores do Nordeste.

Sucessor de Darcy Ribeiro, em junho de 1963, Paulo de Tarso Santos assumiu o Ministério da Educação e, seguindo indicação de seu antecessor, nomeou Paulo Freire diretor do Plano Nacional de Educação. Em 16 de julho, através da Portaria 195, foi instituída a Comissão de Cultura Popular com o objetivo de implantar novos sistemas educacionais de viés eminentemente popular. Paulo Freire foi nomeado presidente desta Comissão e, em 1963, percorreu o país com o objetivo de estruturar o Programa Nacional de Alfabetização. Em 1964, Freire lançou o Plano Nacional de Alfabetização de Adultos, com base na experiência de Angicos.

Não faltaram críticas vindas de setores conservadores e de adversários do governo popular de Goulart. Assim, p. ex., por ocasião da passagem de P. Freire por S. Paulo, o jornal Estado de S. Paulo (8/12/63) publicou um Editorial crítico com o título 'Alfabetizar ou politizar?'. Na semana posterior, em 21/12/63, o mesmo jornal publicou novo Editorial com o título 'Método nazista', atacando diretamente Paulo Freire.

Este foi o início do breve projeto que logo seria interrompido pela ditadura que assumiu o poder com o golpe militar de 1/4/1964. Paulo Freire acabou preso por 70 dias numa cadeia de 
Olinda, acusado de subversivo e ignorante. Em setembro deste mesmo ano, como aconteceu com tantos outros intelectuais, foi condenado ao exílio. Após rápida passagem pela Bolívia, seu destino foi o Chile, onde trabalhou no Instituto de Capacitacón y investigación de la reforma agrária (ICIRA). Lá permaneceu por cinco anos, tempo em que redigiu sua mais importante obra, a Pedagogia do Oprimido (1968). Em 1969, lecionou na Universidade de Harvard nos Estados Unidos e, na década de 70, foi Consultor da Conselho Mundial das Igrejas, em Genebra. Nessa função, teve uma participação importante na educação de Guiné Bissau ${ }^{1}$, Cabo verde e São Tomé e Príncipe. Em 1980, após dezesseis anos de exílio, pode retornar ao Brasil e no mesmo ano passou a lecionar na Universidade Estadual de Campinas e na Pontifícia Universidade Católica de São Paulo.

Quando Luiza Erundina de Souza, do Partido dos Trabalhadores, assumiu a Prefeitura de São Paulo, Paulo Freire esteve à frente da Secretaria de Educação da maior cidade do país (19891991). Inaugurou um novo estilo administrativo de viés democrático/popular, muito diferente do autoritarismo anterior de Jânio Quadros. Foram definidos quatro eixos orientadores da política municipal para a área de educação: democratização da gestão; acesso e permanência; qualidade da educação e educação de jovens e adultos.

Paulo Freire retirou-se da Secretaria em maio de 1991, sendo substituído por Mario Sérgio Cortella. Este ciclo democrático inovador se encerrou com a eleição de Paulo Maluf para Governador (1993) e a nomeação de Sólon Borges dos Reis como Secretário de Educação. Mais uma vez, Freire teve suas ideias amordaçadas e seu projeto educacional interrompido por forças conservadoras que já atuavam durante o regime militar. Era também um período em que assumiam contornos mais nítidos as influências do neoliberalismo econômico que, desde então, vem se impondo como a 'nova razão do mundo' 2 .

Paulo Freire não ensina apenas a ler e a escrever letras e palavras, mas a ler e escrever (mudar) o mundo. Não ensina apenas a decodificar os signos linguísticos, mas a decodificar o mundo. Ernani Maria Fiori (1975, p. 3), na sua introdução à Pedagogia do oprimido, destaca precisamente este aspecto: “A decodificação é análise e consequente reconstituição da situação

\footnotetext{
1 “Este projeto [...], - como as próprias bases de nossa colaboração -, tinha de nascer lá, pensado pelos educadores nacionais em função da prática social que se dá no país” (FREIRE, 1977, p. 17).

${ }^{2}$ No seu livro, A nova razão do mundo, Pierre Dardot e Christan Laval (2016, p. 326) falam da "modelagem da sociedade pela empresa" e definem que "o momento neoliberal caracteriza-se por uma homogeneização do discurso do homem em torno da figura da empresa".
} 
vivida: reflexo, reflexão e abertura de possibilidades concretas de ultrapassagem". A decodificação faz parte do processo de conscientização que concebe a educação como processo político e libertador, concebido em três etapas: a investigação biográfica dos conceitos centrais; a decodificação dos sentidos sociais e a consciência de mundo; e a problematização, ou seja, a superação da visão mágica pela visão crítico/transformadora do mundo.

Este é o sentido mais amplo e profundo que assume em Paulo Freire o conceito alfabetizar. Desde um ponto de vista contemporâneo, a força de Angicos não se coloca em termos de exemplo a ser seguido. Coloca-se, sim, em termos de uma admoestação que chama a atenção para a necessidade permanente de leituras sempre renovadas da realidade. Vivemos hoje num mundo muito distinto daquele, embora ainda com problemas humanos similares. Nosso desafio atual não é alfabetizar, mas desvelar as novas formas de domínio e de exclusão social que a própria alfabetização carrega em seu âmago. Entendo que a obra de Freire deve ser interpretada atualmente como metáfora histórica. Uma metáfora que nos ensina a importância da leitura do sentido humano da história, do reconhecimento da pessoa humana, do seu sentido ontológico, e da justiça social. Para explicitar melhor o que estou a dizer, valho-me de metáfora famosa, escrita por Walter Benjamin (2013, p. 14):

Há um quadro de Klee intitulado Angelus Novus. Representa um anjo, que parece preparar-se para se afastar de qualquer coisa que olha fixamente. Tem os olhos esbugalhados, a boca escancarada e as asas abertas. $\mathrm{O}$ anjo da história deve ter este aspecto. Voltou o rosto para o passado. A cadeia de fatos que aparece diante de nossos olhos é para ele uma catástrofe sem fim que incessantemente acumula ruínas sobre ruínas e as lança aos seus pés. Ele gostaria de parar para acordar os mortos e reconstituir, a partir dos seus fragmentos, aquilo que foi destruído. Mas do paraíso sopra um vendaval que se enrodilha nas suas asas, e que é tão forte que o anjo já não as consegue fechar. Este vendaval arrasta-o imparavelmente para o futuro, a que ele volta as costas, enquanto o monte de ruínas à sua frente cresce até o céu. Aquilo a que chamamos progresso é este vendaval.

\section{II}

Angicos e toda a história posterior do projeto de Paulo Freire é, no meu entender, algo como uma grande metáfora que representa a luta contra a produção da ruina humana que se amontoa aos pés do anjo da história. Os escombros que se amontoam, são os escombros humanos dos excluídos, dos pobres, dos ignorantes, dos analfabetos. As palavras, os projetos, as aulas, enfim, o empenho de Paulo Freire é a luta para parar ou, pelo menos, amainar a tempestade, cujos ventos impedem que as asas do anjo da história se fechem. 
Angicos, entendido como metáfora, assume importância no embate contra o neoliberalismo e sua estratégia econômica de transformar a educação como direito em educação como serviço; Angicos é uma metáfora que nos fala dos riscos da mercantilização da educação pública; Angicos é uma metáfora contra a exclusão social; Angicos é uma metáfora a favor de uma sociedade democrática, justa e inclusiva. O método de Paulo Freire, seu projeto de formação política, quer impedir que os escombros humanos continuem a se acumular aos pés do anjo da história.

O momento político, econômico e cultural que atravessa a sociedade brasileira hoje, é, sob todos os pontos de vista, preocupante. A educação faz parte deste cenário de frustração e incertezas. $\mathrm{O}$ fim da ditadura gerou muitas esperanças que se concretizaram, em termos formais e legais, na Constituição Federal de 1988 e na Lei de Diretrizes e Bases da Educação Nacional de 1996. Seguiram-se quase duas décadas de esforços para realizar as metas estabelecidas nestes dois documentos básicos. Com o passar do tempo e na sucessão dos governos, as esperanças de mudanças mais profundas e duradouras foram se frustrando pelas resistências e defesas dos privilégios das elites, avessas à ideia de uma sociedade mais democrática, justa e igual. O grande sonho de uma educação pública de qualidade para todos esbarrou nos interesses econômicos que transformaram a educação em prestação de serviços oferecidos no mercado como outro produto qualquer.

A história mais recente da educação no Brasil é paradigmática desse cenário. As lutas e conquistas alcançadas e materializadas na realização das CONAES e na elaboração do Plano Nacional de Educação (PNE) foram, aos poucos, ora de forma ostensiva, ora de forma velada, sendo subvertidas e esvaziadas pelas estratégias das elites políticas e econômicas conservadoras. Hoje nos encontramos em um momento de inoperante caos e frustração ao qual nem os mais pessimistas acreditavam pudéssemos um dia chegar. Não se trata apenas de lentidão e paragem, mas de verdadeiro retrocesso, visto que não apenas as elites vêm se reestruturando após as turbulências dos anos 1960 e 70, mas também os setores progressistas perdem seu alento frente às imposições do pragmatismo político e econômico.

O desânimo se traduz na imputação de culpa a certos grupos sociais, agremiações políticas ou mesmo figuras públicas individuais. Nos encontramos em meio a turbulências e torvelinhos de águas turvas, sem saber para onde nos levam. Distraídos pela mídia, tentamos pendurar nossas esperanças em ganchos que a inteligência do sistema nos aponta, e perdemos de 
vista o fluxo do grande rio que não cessa de nos levar, não sabemos para onde. Este é o 'chão fecundo' em que crescem os salvadores da pátria da direita, da esquerda, da mídia, do mercado ou mesmo da religião. Esta visão ampla, talvez, nos ajude a entender melhor o curso, as interconexões e as determinações, bem como as dificuldades em que nos encontramos.

Uma 'nova razão do mundo', na expressão de Pierre Dardot e Christian Laval (2016), assume os rumos no grande cenário do neoliberalismo ou pós-neoliberalismo econômico. Com esta expressão, os autores se referem à nova gestão pública, ou seja, à gestão que aplica às já reduzidas incumbências do Estado os mesmos critérios e procedimentos próprios do neoliberalismo econômico. Sabemos e constatamos que e como se difunde e naturaliza o modo utilitarista como a nova ética, hoje regente das relações humanas. Internalizado, primeiro velada e hoje ostensivamente, o modelo empresarial se torna o 'paradigma ideal' da convivência: o que é bom para o mercado, é bom para os seres humanos. Não mais a sociedade, ou seja, as pessoas moldam o sistema de vida segundo seus interesses e prioridades, mas o modelo empresarial de mercado se torna o paradigma teórico e prático do pensar e do agir. É a 'sacralidade do hic et nunc', do sistema e da máquina, que transforma os, ainda, úteis seres humanos em fantoches monetarizados e monitorados, marginalizando e relegando todos os demais à sua própria sorte. Nos termos de Adorno e Horkheimer (1985, p. 24; 37)

O preço que os homens pagam pelo aumento de seu poder é a alienação daquilo sobre o
que exercem o poder. O esclarecimento comporta-se com as coisas como o ditador se
comporta com os homens. Este conhece-os na medida em que pode manipulá-los. [...] O
pensar reifica-se num processo automático e autônomo, emulando a máquina que ele
próprio produz para que ela possa finalmente substituí-lo.

As águas que transbordam o rio do pragmatismo economicista invadem os territórios do humano, da educação e da cultura, e afogam as plantas que ali cultivamos com carinho e cuidado, impregnando-as com os interesses e objetivos danosos da racionalidade econômica. A introdução da cultura de resultados na educação representa uma verdadeira mutação antropológica. Assim, o ato de julgamento da atividade educacional que deveria se embasar em critérios formativos, tanto racionais quanto éticos e políticos, passa a se orientar em medidas de produtividade e eficiência de corte econômico/empresarial, supostamente neutros.

Tudo é produzido segundo o modelo de mercado: segurança social, aposentadoria, saúde, educação. Na medida em que se retira toda a força (Kratia) do povo (demos), transforma-se 
profundamente a democracia em agoracracia $^{3}$. O poder não está mais com o povo, mas com o mercado. O mercado é considerado a melhor forma de organizar a sociedade, a melhor forma de governar. Em nome dos interesses econômicos sacrifica-se a saúde, a educação, a seguridade social. Uma democracia, economicizada por definição, não é mais democracia porque prevalecem os interesses não da sociedade, do povo, mas da elite econômica.

\section{III}

As pessoas não controlam mais suas vidas; quem as controla são as forças econômicas. $\mathrm{O}$ mercado é importante, não resta dúvida, mas é inadequado que ele nos controle, que controle nossas vidas. Como reação, começam a despontar temas como, alteridade, reconhecimento, resumidos no conceito 'o comum', conforme assinalam em outra obra Michel Dardot os já citados Dardot e Laval (2017) em seu mais recente livro que agora está sendo editado no Brasil: 'Comum'. Na mesma direção, vão as reflexões de Judith Butler (2015) com seus estudos culturais sobre identidade, sobre a episteme do estranho e da diferença na inserção social. Há uma grande dubiedade ética para pessoas que vivem em determinado contexto, dominado pelos valores do mercado, preservar uma postura ética referenciada ao bem comum. Coerência ética, escreve a autora, "para sujeitos que vivem invariavelmente dentro de um horizonte temporal, trata-se de uma norma difícil, quiçá impossível, de ser satisfeita” (p. 60). O mercado se torna algo como um éthos coletivo ao qual há que sujeitar-se em nome da sobrevivência.

Segundo Carlos Alberto Torres (Gadotti; Torres, 1992), Freire se torna ainda mais importante no cenário atual do embate com o neoliberalismo e seu projeto de transformação da educação em serviço, estritamente ligado aos interesses econômicos que hoje dominam o mundo. Por isso, se queremos ser justos com o grande educador brasileiro, se queremos dar conta hoje de seu legado, não podemos limitá-lo ao momento histórico da emergência de sua teoria, mas projetar o essencial de suas ideias sobre a tela do presente. Penso, como já disse anteriormente, que a ideia mais fundamental em Paulo Freire é a ideia de 'povo', da democracia, da justiça social, do direito de todos ao usufruto dos bens materiais e culturais historicamente produzidos e

\footnotetext{
${ }^{3}$ A palavra grega 'ágora' tem um duplo sentido. Pode significar o poder do povo em determinar seu próprio destino, mas pode também significar, mercado. Este é o sentido do termo aqui usado: poder do Mercado.
} 
elaborados pela humanidade. Os bens culturais e materiais, já ensinava Marx, são conquistas e realizações que, portanto, devem ser acessíveis a todos.

Podemos acompanhar a biografia de Freire, vasculhar sua vasta bibliografia, ler seus escritos de frente para trás, de trás para frente ou, então, aleatoriamente e a ideia de 'povo' sempre está presente no que efetivamente importa enquanto referência central. Desde o tempo de Angicos, aqueles trezentos adultos marginalizados e analfabetos eram o povo. Por isto, Freire é atual: o que enuncia e denuncia ao longo de sua trajetória de vida é o que estamos vivendo: a desconstrução do conceito de povo, significando o todo da sociedade. O termo 'povo' passou a ter o sentido pejorativo de 'populaça', 'populacho', 'poviléu, 'povaréu', 'zé-povinho', todos derivados de 'povo', tornaram-se sinônimos de 'escória', 'lixo', 'gentalha', 'multidão'. É isto que nos ensina Wendy Brown em seu recente livro 'Undoing the demos', ou seja, 'desfazendo o povo’. Brown (2015) rastreia a devastadora erosão dos princípios e da cultura democrática pelo neoliberalismo que resulta no desempoderamento do povo. Não mais o povo, mas as elites econômicas decidem sobre o destino da população. Neste mesmo sentido, a elite reserva para si o termo 'alta sociedade' para distinguir-se dos níveis médio e baixo. Este espelhamento conceitual da realidade social e econômica confere às teses de Freire grande relevância e atualidade e relevância para a contemporaneidade.

Mas é preciso cuidado para não restarmos reféns, presos na gaiola de ferro (Weber) do sistema. Judith Buttler nos lembra que não há sujeito preexistente, pois somos todos constituídos no discurso, nos atos de fala e de escuta. Neste sentido, Heidegger (2009, p. 174-175) nos fala do Dasein, do ser aí que designa o ser humano enquanto ser no mundo, ou seja, o ser interhomines, relacional e comunicativo que lhe permite dizer 'eu sou eu mesmo' enquanto um poder-ser, um ser que nunca está pronto, mas que é, sempre, um ser como projeto de seu próprio futuro. Seres humanos "não são algo simplesmente dado e nem algo à mão. São como a própria presença libertadora - são também co-presenças" [...] e "a presença é em si mesma, essencialmente sercom." Ser-com implica horizontalidade no poder-ser. Em termos menos abstratos, podemos dizer que o ser humano se constitui, se constrói em sociedade, o que, por sua vez, implica condições de fazê-lo.

Assim nos acercamos de um segundo conceito essencial em Freire que é a ‘conscientização', por sua vez ligado ao conceito/ideal de 'autonomia'. O ser humano alienado é aquele que não tem consciência de si enquanto sujeito de direito, aquele que permite que lhe 
digam quem é e qual é seu lugar na sociedade. Por isso, a genial estratégia de Freire de conscientização foi o trabalho com o universo vocabular dos conceitos e temas geradores. Genial porque os conceitos representam o centro da cultura humana e, portanto, o fulcro da conscientização. Por isso, os temas geradores não são trazidos de fora, mas colhidos da vida das pessoas para servirem de esteio inteligível para a ideia de conscientização. Este é o ponto criativo, o pulo do gato de Freire, tão perturbador para o sistema opressor do militarismo que não viu outra alternativa senão prendê-lo e mandá-lo para o exílio.

Freire era perigoso porque ele e seus colaboradores foram primeiro escutar, conhecer a realidade, sentir o sentir dos excluídos, para, a partir daí, criar a base de um diálogo constituinte de subjetividade, de consciência. O que o autoritarismo não tolera é a conscientização dos oprimidos. Gerar consciência é romper este círculo da alienação, é gerar a ambiência que torna possível a construção do sujeito por ele mesmo. Para isto, ele precisa do outro, do educador, daquele que o ajuda a conquistar consciência de si mesmo como sujeito de direitos, como condição de sua humanidade. Esta é a razão porque o educador é perigoso para o sistema opressor.

A pior escravidão do ser humano é a escravidão conceitual. Escravidão conceitual ocorre quando o ser incorpora conceitos que explicam e orientam sua vida introjetando a ideia da inferioridade, de submissão, de ignorância. Era este sentido profundo de escravidão conceitual, de escravidão invisível e internalizada que Freire buscava trazer à luz e romper. Na escravidão conceitual já não há espaço para a reação, para a resistência, para a revolta; é a aceitação da condição de inferioridade. Paulo Freire quis romper com isso; quis abrir perspectivas; quis dizer que mudanças são possíveis. Por isso, sua pedagogia é uma pedagogia do possível, da esperança, da utopia, do rompimento com a fatal escravidão conceitual.

Nesta questão pouco mudou de lá para cá. A razão de porque a Conferência Nacional de Educação (CONAES) foi esvaziada; porque o Plano Nacional de Educação foi desfigurado; porque os recursos das áreas de educação, de saúde, dos programas sociais foram congelados por vinte anos; porque a educação superior foi privatizada em cerca de $80 \%$; porque foi concebido o Projeto de Lei denominado 'Escola sem partido', visando silenciar as vozes críticas ao regime neoliberal, é a mesma: o domínio, a riqueza, o privilégio e o deleite da elite. É também por isso que o ethos freireano da conscientização, da igualdade, do direito ao debate e à discussão está 
sendo silenciado. Interessante observar que os defensores do Projeto de Lei 'Escola sem Partido' atacam Paulo Freire acusando-o de marxista, seguindo o exemplo dos militares em 1964.

\section{Conclusão}

Para finalizar, gostaria de retomar, por um instante, o conceito de luta, tão presente nos textos de Freire. Sabe-se que o motivo da luta à qual Freire consagrou sua vida não está superado. Embora não seja o momento de mencionar estatísticas, todos sabemos que o problema da marginalização, do analfabetismo, da exclusão social e mesmo do analfabetismo, sobretudo o funcional, está longe de ser superado no Brasil. Muitas coisas mudaram desde a despedida de Freire, mas na essência os problemas persistem. Hoje vivemos sob uma nova forma de ditadura: a ditadura do capitalismo neoliberal que, por definição, condena a maior parte da população à exclusão, à marginalidade, ao desemprego, à fome e à miséria. O capitalismo, sobretudo na sua versão mais selvagem como a que vige no Brasil, gerou novas formas de marginalização não menos graves que as anteriores, ainda que sob novas formas, mais palatáveis e estetizadas que visam desresponsabilizar o sistema econômico e culpabilizar os excluídos por sua ignorância, sua falta de competitividade.

A educação está sendo profundamente envolvida nesse jogo de vida ou morte; de um lado, pela oferta de educação de excelência para a elite que pode pagar altas mensalidades e, de outro, pelo abandono da escola pública, pelo desleixo da formação docente, pelas péssimas condições de trabalho e pelos salários indecentes. A educação serve ao sistema, a pessoa serve ao sistema. Enfim, servir ao sistema se transformou no sentido da vida. Paulo Freire se encontra no divisor de águas entre o ideal dos grandes educadores de pensamento crítico/idealista e a realidade pragmático/sistêmica. Na visão do seu tempo, sobretudo nos anos iniciais, Freire é revolucionário/inovador. Na perspectiva sistêmico/economicista de hoje pode parecer ingênuo e inofensivo. Esse é precisamente o dilema da escola: formar pessoas humanas ou profissionais competentes. Ambas parecem inarredáveis; o desafio é combiná-las. Ou ampliamos o discurso de Paulo Freire, na perspectiva do novo momento histórico ou lhe faremos a injustiça de imobilizar suas ideias no enredo do passado. 


\section{Referências}

ADORNO, Theodor; HORKHEIMER, Max. Dialética do esclarecimento. Rio de Janeiro: Jorge Zahar, 1985.

BENJAMIN, Walter. O anjo da história. Belo Horizonte: Autêntica, 2013.

BROWN, Wendy. Undoing the people: neoliberalism's stealth revolution. Cambridge: Zone Books, 2015.

BUTLER, Judith. Relatar a si mesmo: crítica da violência ética. Belo Horizonte: Autêntica, 2015.

DARDOT, Pierre; LAVAL, Christian. A nova razão do mundo. São Paulo: Boitempo, 2016.

DARDOT, Pierre; LAVAL, Christian. Comum. São Paulo: Boitempo, 2017.

O ESTADO DE S. PAULO. São Paulo, ano 42, 08 dez. 1963.

O ESTADO DE S. PAULO. São Paulo, ano 42, 21 dez. 1963.

FIORI, Ernani Maria. Aprenda a dizer sua palavra. Rio de Janeiro: Paz e Terra, 1975.

FREIRE, P. Pedagogia do oprimido. Rio de Janeiro: Paz e Terra, 1968.

FREIRE, Paulo. Cartas à Guiné-Bissau. Rio de Janeiro: Paz e Terra, 1977.

GADOTTI, Moacir; TORRES, Alberto. Estado e educação popular na América Latina. Campinas: Papirus, 1992.

HEIDEGGER, Martin. Ser e tempo. Petrópolis: Vozes, 2009.

Pedro Laudinor Goergen

Uniso | Programa de Pós-Graduação em Educação

Sorocaba | SP | Brasil. Contato: pedro.goergen@hotmail.com

ORCID 0000-0001-9539-9752 